\title{
Análise Prospectiva com Ênfase Científica e Tecnológica do Gênero Erythrina (Fabaceae) \author{
Genus Erythrina (Fabaceae)
} \\ Prospective Analysis with Scientific and Technological Envelope of the
}

\author{
Adonias Almeida Carvalho ${ }^{1,2}$ \\ Luanda Ferreira Floro da Silva² \\ Jurema Santana de Freitas ${ }^{2}$ \\ Rodrigo Ferreira Santiago ${ }^{2}$ \\ Mariana Helena Chaves ${ }^{2}$ \\ ${ }^{1}$ Instituto Federal do Piauí, Piripiri, PI, Brasil \\ ${ }^{2}$ Universidade Federal do Piauí, Teresina, PI, Brasil
}

\begin{abstract}
Resumo
O gênero Erythrina (Fabaceae) compreende 100 espécies de plantas de valor comercial e com propriedades biológicas importantes. O objetivo deste estudo foi realizar uma prospecção científica e tecnológica do gênero Erythrina. Os bancos de patentes pesquisados foram o European Patent Office (EPO), o Instituto Nacional da Propriedade Industrial (INPI) do Brasil, o Banco de Patentes Latino-Americanas (LATIPAT), o United States Patent and Trademark Office (USPTO) e o World Intellectual Property Organization (WIPO). A maioria das patentes está depositada na EPO e WIPO com 271 e 234 registros, respectivamente. O crescimento no número de patentes depositadas ocorreu a partir de 2010. A China, os Estados Unidos, o Canadá e o Japão são os principais depositantes de patentes envolvendo as espécies de Erythrina nas bases EPO e WIPO. As classificações internacionais mais frequentes das patentes foram A61K, seguida de A61P e C12N.
\end{abstract}

Palavras-chave: Erythrina. Fabaceae. Prospecção Tecnológica.

\begin{abstract}
The genus Erythrina (Fabaceae) comprises 100 species of plants of commercial value and with important biological properties. The objective of this study was to carry out a scientific and technological survey of the genus Erythrina. The patent banks surveyed were the European Patent Office (EPO), the National Institute of Industrial Property of Brazil (INPI), the Latin American Patent Bank (LATIPAT), the United States Patent and Trademark Office (USPTO) and the World Intellectual Property Organization (WIPO). Most patents are deposited in the EPO and WIPO with 271 and 234 registrations, respectively. The growth in the number of patents deposited occurred as of 2010. China, the United States, Canada and Japan are the main patent depositors involving Erythrina species in the EPO and WIPO bases. The most frequent international patent classifications were A61K, followed by A61P and C12N.
\end{abstract}

Keywords: Erythrina. Fabaceae. Technological Prospecting.

Área Tecnológica: Prospecção Tecnológica. 


\section{Introdução}

Produtos naturais têm despertado interesse nos principais centros de pesquisa do mundo, não apenas pela sua eficácia na cura de doenças, como também devido à acessibilidade e à viabilidade econômica (SILVA et al., 2013). A aplicação de plantas medicinais no tratamento e na cura de enfermidades é tão remota quanto a espécie humana e, para inúmeros centros comunitários, essa prática representa o único recurso terapêutico disponível (MACIEL et al., 2002). O Brasil possui uma grande diversidade biológica, em seu espaço geográfico constam aproximadamente $22 \%$ das espécies de plantas superiores do planeta e inúmeras delas com potencial mercadológico nos setores farmacêutico, alimentício, cosmético, entre outros (BRASIL, 2002; SILVA et al., 2013).

O número elevado de pesquisas sobre espécies vegetais realizadas nos últimos anos agrega valores científicos e ainda evidencia um crescimento no interesse por produtos naturais. Espécies vegetais são fontes importantes de substâncias com potencial farmacológico, especialmente devido à grande variedade de classes de metabólitos secundários de natureza química variada (PATRA et al., 2013; TULP; BOHLIN, 2004). Nesse sentido, a família Fabaceae destaca-se por possuir um número expressivo de espécies de interesse comercial, industrial e medicinal. São plantas de hábitos variados, desde grandes árvores das matas tropicais até arbustos e subarbustos (LEWIS et al., 2005).

A família Fabaceae é composta de seis subfamílias: Papilionoideae (503 gêneros, cerca de 14.000 espécies), Caesalpinioideae (148 gêneros, cerca de 4.400 espécies; incluindo os gêneros do clado Mimosoideae), Detarioideae (84 gêneros, cerca de 760 espécies), Dialioideae (17 gêneros, cerca de 85 espécies), Cercidoideae (12 gêneros, cerca de 335 espécies) e Duparquetioideae (1 gênero, 1 espécie) (LPWG, 2017). Plantas dessa família são utilizadas em formas variadas, como na alimentação, nas indústrias madeireiras, de fibras, de óleos e de compostos químicos. São constituídas por várias classes de metabólitos secundários, entre eles, flavonoides, incluindo rotenoides e isoflavonoides; alcaloides; terpenoides e esteroides (WOJCIECHOWSKI; LAVIN; SANDERSON, 2004). No Brasil, a subfamília Papilionoideae é representada pelos gêneros Dalbergia (jacarandá-da-bahia e violeta), Dipteryx (baru e cumaru-ferro), Erythrina (corticeiras ou suinãs) e Machaerium (jacarandás).

O gênero Erythrina é constituído por cerca de 115 espécies distribuídas em todas as regiões tropicais do mundo, estendendo-se nas áreas quente-temperadas, como no Sul da África, na Cordilheira do Himalaia e no Sudeste dos Estados Unidos. O termo Erythrina, do latim erythros, significa vermelho em referência às cores vermelhas ou alaranjadas das flores de espécies deste gênero (SCHLEIER; QUIRINO; RAHME, 2016).

As plantas do gênero Erythrina possuem elevada importância econômica, são usadas na confecção de palitos, brinquedos, fósforos e urnas funerárias. Na medicina tradicional são utilizadas na prevenção de doenças no fígado, como calmante de tosse, disenteria, asma, dor estomacal, infertilidade feminina, infecções microbianas e possuem ainda efeitos tranquilizantes e paralisantes (FARIAS et al., 2007; RIBEIRO et al., 2006; SCHLEIER; QUIRINO; RAHME, 2016). Estudos farmacológicos têm comprovado que espécies desse gênero apresentam atividades antimalárica, antituberculose, citotóxica e pró-apoptótica (NYANDORO et al., 2017; PASSREITER et al., 2015). 
Nesse contexto, o presente trabalho teve como objetivo realizar uma prospecção científica e tecnológica de espécies do gênero Erythrina a fim de analisar o número de depósitos de patentes em bancos de inovação e tecnologia nacional e internacional. Adicionalmente, pretende-se aqui descrever o perfil da produção científica nas áreas de química e farmacologia por meio da análise de artigos publicados em periódicos científicos no intervalo entre 2010 a 2017, período marcado pela intensificação no número de depósitos de patentes.

\section{Metodologia}

A prospecção tecnológica sobre o gênero Erythrina foi realizada com base nos depósitos de patentes dos bancos de dados European Patent Office (EPO), Instituto Nacional da Propriedade Industrial (INPI) do Brasil, Banco de Patentes Latino-Americanas (LATIPAT), United States Patent and Trademark Office (USPTO) e World Intellectual Property Organization (WIPO). Para realizar o levantamento dos artigos científicos, utilizou-se as bases de dados Science Direct, Scientific Electronic Library Online (SciELO), Scopus e Web of Science, pesquisando-se em títulos e em resumos.

A busca de anterioridade dos artigos científicos ocorreu entre junho e agosto de 2017, por meio da utilização da palavra-chave Erythrina, sendo considerados válidos os documentos que mencionassem esse termo no título e/ou resumo. O período pesquisado das patentes depositadas foi a partir 1940, data do primeiro depósito e se estendeu até 2017. Em seguida, foram escolhidos os bancos de dados que apresentaram os maiores números de documentos depositados, sendo esses posteriormente analisados quanto ao país depositário, ano de depósito e Classificação Internacional de Patentes (CIP). Considerou-se para a realização da pesquisa de artigos científicos o período dos últimos 10 anos (2008-2017), quando ocorreu a intensificação no número de depósito de patentes. Os documentos encontrados foram considerados válidos para a análise.

\section{Resultados e Discussão}

Estudos de prospecções tecnológicas são valiosos instrumentos para mensuração e avaliação do desenvolvimento técnico, científico e socioeconômico de um país. Em diversos países, o estudo serve como parâmetro para direcionar as pesquisas científicas, delinear a indústria sobre os recursos naturais, além de subsidiar tomadas de decisões, fundamentar políticas estratégicas para inovação e identificar oportunidades futuras para vários indicadores sociais (TEIXEIRA, 2013; OLIVEIRA et al., 2013).

\subsection{Distribuição de Patentes por Base}

Ao pesquisar nas bases de dados de patentes com a palavra-chave Erythrina (Figura 1), verificou-se a existência de um total de 521 documentos envolvendo esse gênero, distribuídos nas bases EPO (271), WIPO (234), LATIPAT (8), USPTO (6) e INPI (2). 
Figura 1 - Número de patentes sobre Erythrina depositadas nas bases EPO, WIPO, USPTO, LATIPAT e INPI

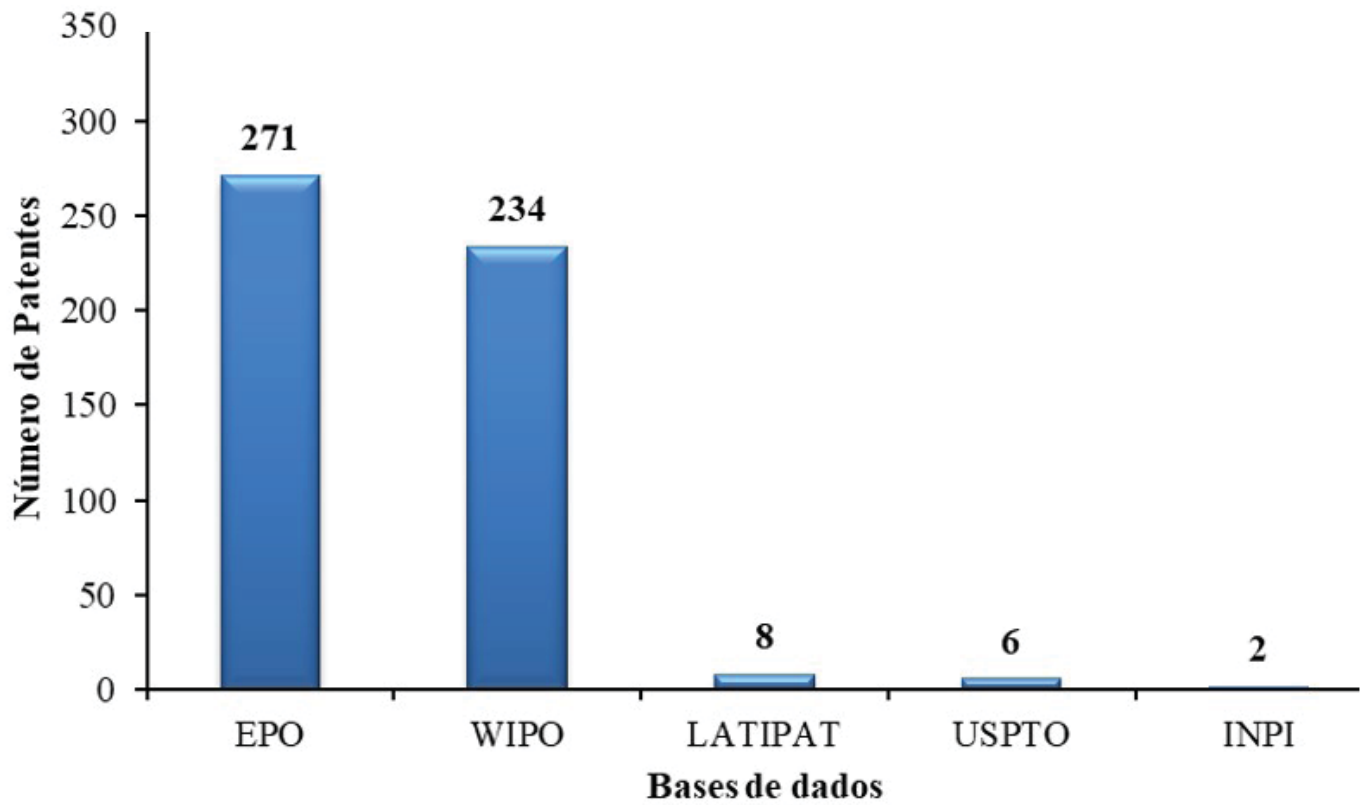

Fonte: Elaborada pelos autores deste artigo (2017)

A instituição brasileira, o INPI, foi a que menos se destacou em número de patentes envolvendo o gênero Erythrina, pois só apresentou dois depósitos, um envolvendo um composto fitoterápico para o tratamento da menopausa e outro referente a uma metodologia analítica para a caracterização e obtenção de compostos químicos a partir de extratos de Erythrina mulungu, nos anos de 2008 e 2010 (Tabela 1). O número pouco expressivo de patentes no INPI mostra que a produção tecnológica dos pesquisadores brasileiros é ainda escassa quando comparada a outros países. No entanto, isso revela um cenário de possibilidades para investimentos em estudos voltados para pesquisa, inovação e desenvolvimento de tecnologias, visando um melhor aproveitamento da biodiversidade brasileira.

Tabela 1 - Documentos sobre o gênero Erythrina depositados na base brasileira, INPI

\begin{tabular}{cccc} 
Pedido & DePósito & Título & CIP \\
PI 1004437-0 & $21 / 05 / 2010$ & $\begin{array}{c}\text { Composto fitoterápico para tratamento de } \\
\text { transtornos da menopausa e peri-menopausa }\end{array}$ & A61K 36/185 \\
\hline PI 0800530-3 & $01 / 02 / 2008$ & $\begin{array}{c}\text { Tecnologia analítica baseada na pirólise acoplada à } \\
\text { cromatografia gasosa/espectrometria de massa para } \\
\text { caracterização e obtenção de compostos químicos a partir de } \\
\text { extratos de Erythrina mulungu Linné secos por nebulização }\end{array}$ & C07C 4/04
\end{tabular}

Fonte: INPI (2017) e Classificação Internacional de Patente (CIP)

As bases EPO e WIPO possuem um número maior de patentes depositadas, de modo que a pesquisa foi direcionada para exploração de informações a respeito da distribuição de patentes por país, ano de depósito e por Classificação Internacional de Patente (CIP). Esses resultados foram comparados com as informações encontradas nas outras bases de patentes, quando considerados pertinentes. 


\subsection{Distribuição de Patentes por País}

Os dados apresentados na Figura 2 mostram que, na base EPO, a China, os Estados Unidos e o Japão são os maiores detentores de patentes envolvendo espécies do gênero Erythrina, sendo que a China lidera o ranking com 231 patentes depositadas (85,6\%), seguido pelos Estados Unidos com 14 patentes (5,2\%), Japão com 12 (4,4\%) e Canadá com oito (3\%). África do Sul, Alemanha e México também têm patentes depositadas, porém em número pouco expressivo. $\mathrm{O}$ Brasil não aparece como depositário de patentes na base EPO, mesmo sendo o país que detém a maior biodiversidade do planeta e possuir 12 espécies do gênero Erythrina, algumas com indicação de uso popular, inclusive com utilização pelas indústrias alimentícia e farmacêutica (SCHLEIER; QUIRINO; RAHME, 2016).

Figura 2 - Distribuição de patentes sobre Erythrina depositadas por países no banco de dados da EPO e WIPO

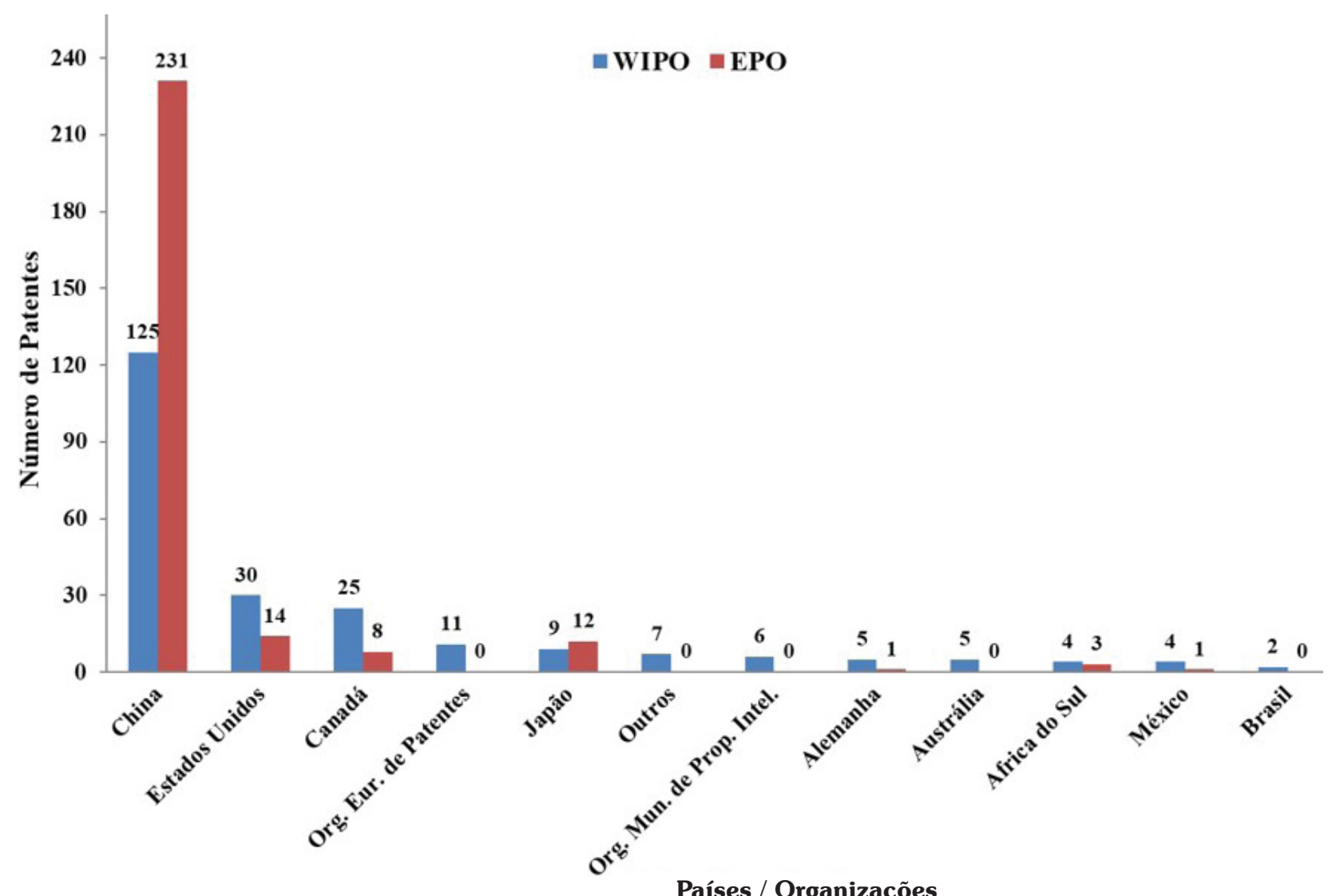

Fonte: Elaborada pelos autores deste artigo (2017)

A análise dos depósitos de patentes na base WIPO revela que a China é também o principal país depositante, apresentando 125 documentos registrados, correspondendo a 53,6\% de todos os documentos sobre o gênero Erythrina depositados nessa base, corroborando com os resultados encontrados na base EPO. Estados Unidos, Canadá e Japão também apresentaram participação significativa no depósito de patentes envolvendo o gênero Erythrina, com 30 (12,9\%), 25 (10,7\%) e 9 (3,9\%) depósitos, respectivamente. 


\subsection{Distribuição de Patentes por Ano}

Em 1940 foi realizado o primeiro registro de patente na base EPO (Figura 3). No período de 1940 a 2009 observou-se uma tendência constante no número de depósitos. A partir de 2010, verificou-se um crescimento significativo atingindo o número máximo nos anos de 2015 e 2016, ambos com 37 documentos, o que corresponde a 13,7\% do número total de patentes com o gênero Erythrina na base EPO. No período de 2010 a 2017, foram depositadas 207 patentes, representando $76,4 \%$ do total de documentos existentes.

Figura 3 - Evolução anual dos depósitos de patentes sobre Erythrina na base EPO e WIPO

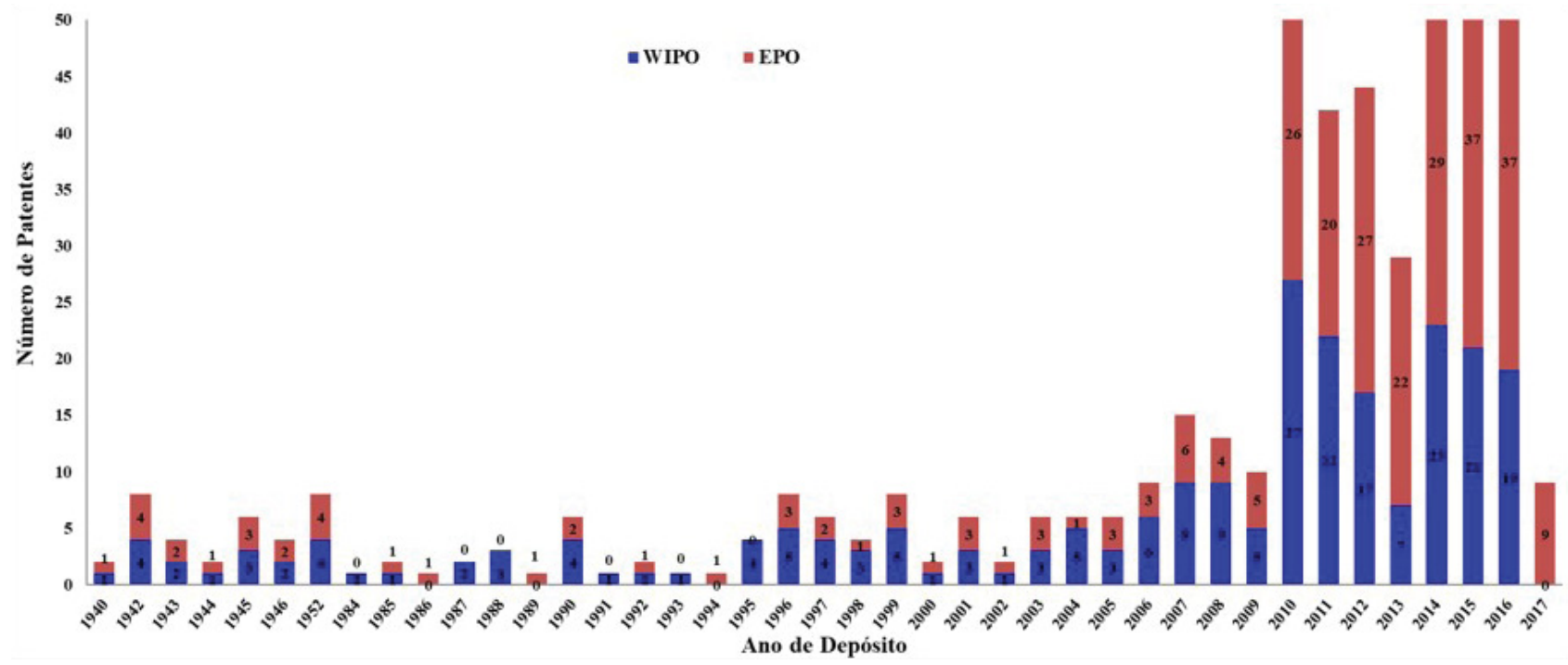

Fonte: Elaborada pelos autores deste artigo (2017)

Em consonância com os resultados observados na base de dados EPO, o primeiro registro de patente envolvendo espécies do gênero Erythrina na WIPO ocorreu também em 1940. De acordo com os dados dessa base, o número de depósitos também vem aumentando gradativamente, sendo que no período de 2010 a 2017 foram depositadas 102 patentes, representando $43,7 \%$ do total de documentos registrados na WIPO com plantas desse gênero. O maior número de patentes foi depositado em 2010 (27 documentos), o que reafirma o interesse em espécies desse gênero no desenvolvimento de novos produtos e/ou processos tecnológicos.

\subsection{Distribuição de Patentes por CIP}

A Classificação Internacional de Patentes (CIP) é uma ferramenta útil para facilitar as buscas em bases de patentes, de modo que torna mais eficiente uma prospecção tecnológica. $\mathrm{Na}$ CIP as patentes são classificadas de acordo com as aplicações. São divididas em 8 seções, 21 subseções, 120 classes, 628 subclasses e 69.000 grupos (SERAFINI et al., 2012; SOUSA; SOUSA; CHAVES, 2016). Dessa forma, as patentes depositadas na EPO utilizando a palavra-chave Erythrina foram analisadas conforme a CIP (Figura 4) e demostraram que o maior número foi registrado nas seções $\mathrm{A}$ (necessidades humanas) e $\mathrm{C}$ (química, metalurgia). Entre os 271 depósitos de patentes encontrados na base EPO, 164 estão alocados na subclasse A61K, que trata de preparações para finalidades médicas, odontológicas ou higiênicas, representando $60,5 \%$ do total. Em segundo lugar está a subclasse A61P (atividade terapêutica específica de 
compostos químicos ou preparações medicinais), que se destacou por apresentar 46 patentes registradas (17\%). Um número expressivo de patentes está inserido nas subclasses $\mathrm{C} 12 \mathrm{~N}$ (micro-organismos ou enzimas e suas composições) e A01N (conservação de corpos de seres humanos ou animais ou plantas ou partes dos mesmos; biocidas, desinfetantes, pesticidas, herbicidas; repelentes ou atrativos de pestes; reguladores do crescimento de plantas), apresentando 25 e 10 documentos, respectivamente. Além disso, também foram encontrados registros de patentes inseridas nas subclasses A23L e C07D.

Figura 4 - Classificação das patentes sobre o gênero Erythrina depositadas nas bases EPO e WIPO de acordo com a CIP

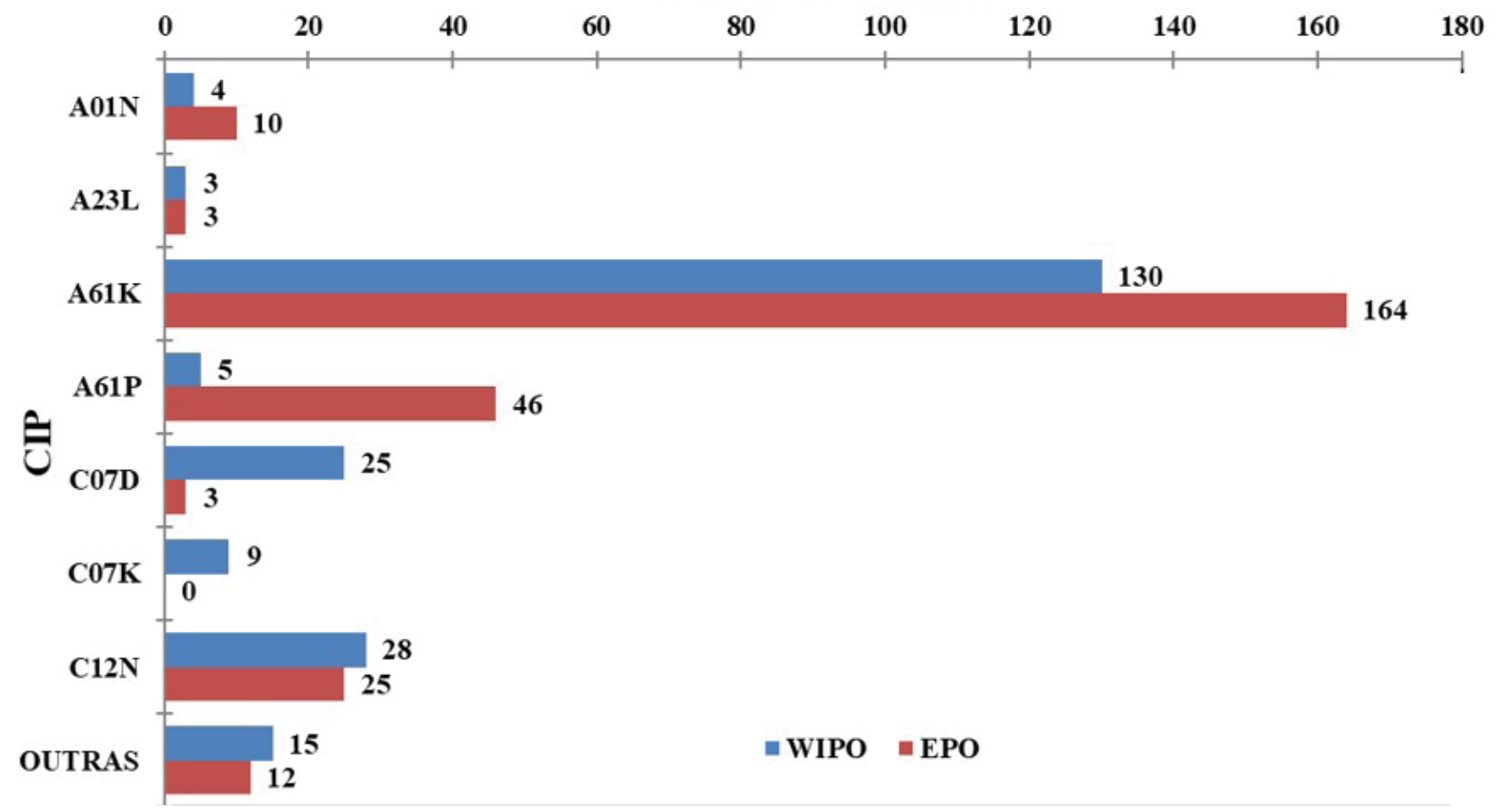

Fonte: Elaborada pelos autores deste artigo (2017)

Comportamento similar sobre a classificação das patentes na base EPO também foi observado na WIPO com participação significativa das subclasses A61K, C12N e C07D. De acordo com os documentos encontrados na WIPO, a subclasse A61K apresentou o maior número de patentes (130, no total), seguido pelas subclasses C12N e C07D, com 28 e 25 patentes, respectivamente. Esses dados mostram o interesse na utilização de espécies do gênero Erythrina no desenvolvimento de preparações com finalidades médicas, odontológicas e/ou higiênicas.

\subsection{Publicações Científicas com Espécies do Gênero Erythrina nos Bancos de Dados}

Nessa prospecção, verificou-se que a maioria dos artigos com plantas do gênero Erythrina foi publicada no período de 2008 a 2017, sobretudo indexados, na Web of Science, Science Direct, SciELO e Scopus (Figura 5). Observa-se que os números mais expressivos de publicações foram registrados no Science Direct (919 artigos), seguido por Scopus (808 artigos), Web of Science (681 artigos) e SciELO (99 artigos). Tomando por base os dados publicados na base Web of Science, pôde-se verificar que os três países que mais publicaram artigos sobre o tema foram o Brasil com 
155 artigos (22,8\%), os Estados Unidos com 74 artigos (10,9\%) e a Índia com 71 artigos (10,4\%). Verificou-se que houve uma intensificação das publicações a partir de 2010, com seu auge em 2014. Embora o Brasil seja o país que mais publicou sobre o tema nos últimos 10 anos, considerando a base Web of Science, esses estudos não refletiram no aumento do número de patentes. Portanto, faz-se necessário estimular a pesquisa e o desenvolvimento de políticas que interliguem a inovação tecnológica com o meio acadêmico que é o celeiro de pesquisadores para tornar o Brasil competitivo do ponto de vista tecnológico. A base Scopus mostra o Brasil como o país que mais publicou sobre o tema no período de 2008 a 2017, com 166 artigos (20,5\%), seguido da Índia com 136 artigos (16,8\%) e dos Estados Unidos com 81 artigos (10,0\%). Enquanto a base SciELO mostrou o Brasil, México e Colômbia como os três países que mais publicaram sobre o gênero Erythrina nos últimos 10 anos, com 87 (64,9\%), 16 (11,9\%) e oito $(6,0 \%)$ artigos, respectivamente. A base de dados Science Direct não apresenta estratificação por país em relação aos artigos científicos.

Figura 5 - Publicações científicas sobre o gênero Erythrina nos últimos 10 anos (2008 a 2017) depositadas nos bancos de dados Science Direct, SciELO, Scopus e Web of Science

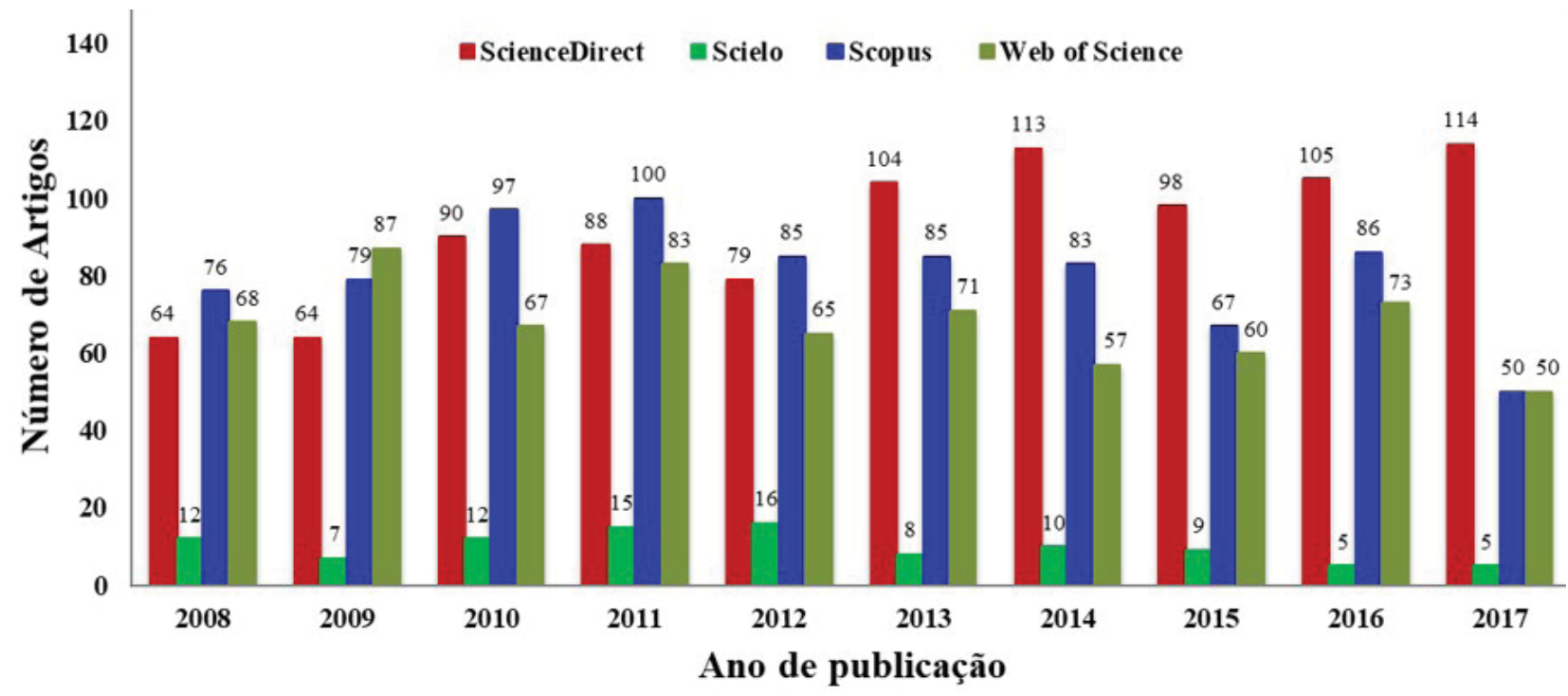

Fonte: Elaborada pelos autores deste artigo (2017)

\section{Considerações Finais}

Os resultados obtidos desta prospecção em relação aos depósitos de patentes nas bases de dados tecnológicas com plantas do gênero Erythrina revelam a importância de execução de estudos de inovação tecnológica e desenvolvimento de novos produtos com espécies deste gênero. A China é o principal depositante seguido pelos Estados Unidos e Japão. O Brasil se destacou como o país que mais publicou artigos científicos sobre o tema no período de 2008 a 2017, considerando as bases Web of Science, Scopus e SciELO. Os pedidos de patentes de origem brasileira ainda são incipientes, embora existam no Brasil pelo menos 12 espécies do gênero Erythrina, muitas delas com indicação de uso tradicional e comprovadas ações farmacológicas. Assim, é necessário incentivar a prática da inovação tecnológica, estimulando o desenvolvimento de novos produtos que envolvam espécies do gênero Erythrina para aproveitar, da melhor forma possível, a biodiversidade brasileira. 


\section{Referências}

BRASIL. Ministério do Meio Ambiente (MMA). Avaliação e identificação de áreas e ações prioritárias para a conservação, utilização sustentável e repartição dos benefícios da biodiversidade nos biomas brasileiros. Brasília: MMA/SBF, 2002. 404p. Disponível em: www. mma.gov.br/estruturas/chm/_arquivos/biodivbr.pdf. Acesso em: 18 out. 2017.

FARIAS, T. J. et al. Alcalóides de flores e folhas de Erythrina speciosa Andrews. Química Nova, [S.l.]. v. 30, n. 3, p. 525-527, 2007.

LEWIS, G. P. et al. Legumes of the World. London: Royal Botanic Gardens, Kew, 2005. 577p.

LPWG - LEUME PHYLOGENY WORKING GROUP. A new subfamily classification of the Leguminosae based on a taxonomically comprehensive phylogeny. Taxon, [S.l.], v. 66, p. 44-77, 2017.

MACIEL, M. A. M. et al. Plantas medicinais: a necessidade de estudos multidisciplinares. Química Nova, [S.I.], v. 25, n. 3, p. 429-438, 2002.

NYANDORO, S. S. et al. Flavonoids from Erythrina schliebenii. Journal of Natural Products, [S.l.], v. 80, n. 2 , p. $377-384,2017$.

OLIVEIRA, F. R. A. M. et al. Prospecção tecnológica do acetato de carvacrolila e aplicações no setor industrial farmacêutico: ênfase em doenças negligenciadas. Revista Geintec, [S.l.], v. 3, n. 3, p. 103-110, 2013.

PASSREITER, C. M. et al. Prenylated flavanone derivatives isolated from Erythrina addisoniae are potent inducers of apoptotic cell death. Phytochemistry, [S.I.], v. 117, p. 237-244, 2015.

PATRA, B. et al. Transcriptional regulation of secondary metabolite biosynthesis in plants.

Biochimica et Biophysica Acta, [S.1.], v. 1.829, p. 1.236-1.247, 2013.

RIBEIRO M. D. et al. Effect of Erythrina velutina and Erythrina mulungu in rats submitted to animal models of anxiety and depression. Brazilian Journal of Medical and Biological Research [S.l.], v. 39, p. 263-270, 2006.

SCHLEIER, R.; QUIRINO, C. S.; RAHME, S. Erythrina mulungu - descrição botânica e indicações clínicas a partir da antroposofia. Arte Médica Ampliada, [S.l.], v. 36, n. 4, p. 162-167, 2016.

SERAFINI, M. R. et al. Mapeamento de tecnologias patenteáveis com o uso da hecogenina. Revista Geintec, [S.l.], v. 2, n. 5, p. 427-435, 2012.

SILVA, J. C. et al. Modelos experimentais para avaliação da atividade antinociceptiva de produtos naturais: uma revisão. Brazilian Journal of Pharmacy, [S.I.], v. 94, p. 18-23, 2013.

SOUSA, R. P.; SOUSA, J. S. M. O.; CHAVES, M. H. Scientific and technological forecasting of the genus Simaba Aubl. (Simaroubaceae). Revista Geintec, [S.l.], v. 6, n. 3, p. 3.343-3.355, 2016.

TEIXEIRA, L. P. Prospecção tecnológica: importância, métodos e experiências da Embrapa Cerrados. Planaltina, DF: Embrapa Cerrados, 2013.

TULP, M.; BOHLIN, L. Unconventional natural sources for future drug discovery. Drug Discovery Today, [S.I.], v. 9, p. 450-458, 2004. 
WOJCIECHOWSKI, M. F.; LAVIN, M.; SANDERSON, M. J. A phylogeny of legumes (Leguminosae) based on analysis of the plastid Matk gene resolves many well-supported subclades within the family. American Journal of Botany, [S.l.], v. 91, n. 11, p. 1.846-1.862, 2004.

\section{Sobre os Autores}

\section{Adonias Almeida Carvalho}

E-mail: adoniasac@hotmail.com

Mestre em Química pela Universidade Federal do Piauí (2013).

Endereço profissional: Av. Rio dos Matos, s/n, Germano, Piripiri, PI. CEP: 64260-000.

\section{Luanda Ferreira Floro da Silva}

E-mail: luandafloro@hotmail.com

Mestre em Química pela Universidade Federal do Piauí (2019).

Endereço profissional: Campus Universitário Ministro Petrônio Portella, Ininga, Teresina, PI. CEP: 64049-550.

\section{Jurema Santana de Freitas}

E-mail: jurema.santana.freitas@gmail.com

Graduanda em Química pela Universidade Federal do Piaú.

Endereço profissional: Campus Universitário Ministro Petrônio Portella, Ininga, Teresina, PI. CEP: 64049-550.

\section{Rodrigo Ferreira Santiago}

E-mail: rodrigosantiago272@hotmail.com

Graduando em Química pela Universidade Federal do Piaú́.

Endereço profissional: Campus Universitário Ministro Petrônio Portella, Ininga, Teresina, PI. CEP: 64049-550.

\section{Mariana Helena Chaves}

E-mail:mariana@ufpi.edu.br

Doutora em Química pela Universidade de São Paulo (1996).

Endereço profissional: Campus Universitário Ministro Petrônio Portella, Ininga, Teresina, PI. CEP: 64049-550. 